\title{
Status of Novel Cardiovascular Risk Factor and Cardiovascular Disease Risk in an Urban Cuban Population-A Pilot Study
}

\author{
Arturo Rodriguez-Ojea', Celia Alonso², John W.G. Yarnell ${ }^{3}$, and Jayne V. Woodside ${ }^{3}$ \\ 'Faculty of Medicine, Calixto Garcia, Havana, Cuba, ${ }^{2}$ Hermanos Ameijeiras Hospital, Havana, Cuba, and \\ ${ }^{3}$ Centre for Public Health, Queen's University Belfast, Belfast, UK
}

\begin{abstract}
Cardiovascular disease is the main cause of death in Cuba, yet the prevalence of novel risk factors is not known. To examine the prevalence of risk factors of traditional and novel cardiovascular diseases (CVDs) among an urban Cuban population, a cross-sectional pilot survey was undertaken in Havana city, Cuba. Ninety-seven adults aged 45-60 years registered to receive medical care at a policlinic. The prevalences of rates of CVD risk factors were: hypertension $(\geq 140 / 90 \mathrm{mmHg})(53.6 \%)$, hypercholesterolaemia (total cholesterol $>5.2 \mathrm{mmol} / \mathrm{L})(47.0 \%)$, low high-density lipoprotein (HDL)-cholesterol ( $<1.03 \mathrm{mmol} / \mathrm{L})(64.3 \%)$; diabetes (self-reported) (24.6\%); metabolic syndrome (ATP III criteria) (58.2\%); overweight and obesity (body mass index $\geq 25 \mathrm{~kg} / \mathrm{m}^{2}$ ) (78.0\%); current smoking (39.3\%); elevated level of C-reactive protein (3 $<$ value $<10 \mathrm{mg} / \mathrm{L})(32.1 \%)$, low lipid-standardized vitamin E levels $(<5 \mu \mathrm{mol} / \mathrm{mmol}$ of total cholesterol) (69.6\%); and high tHcy levels ( $>15 \mu \mathrm{mol} / \mathrm{L})(11.1 \%)$. The total carotenoid status was independently associated with waist-circumference and risk of diabetes and metabolic syndrome. In this small unrepresentative sample of people aged 40-65 years from Havana city, there was a high prevalence of traditional and novel CVD risk factors. The total serum carotenoid status appeared to be associated with an increased prevalence of CVD risk factors.
\end{abstract}

Key words: Cardiovascular diseases; Carotenoids; Cross-sectional studies; Obesity; Risk factors; Cuba

\section{INTRODUCTION}

Cardiovascular diseases (CVDs) are the main cause of death in Cuba (1). Although the mortality rates have decreased in the last 15-20 years, the mortality rates are still among the highest in the Americas (2). There is also a high prevalence of overweight and obesity in Cuba (3). The observed reduction in mortality due to CVDs has been less than would have been expected from the reduction in total serum cholesterol levels, and it has been proposed that this could be due to more novel CVD risk factors (4). The proposed novel risk factors for CVDs include the inflammatory marker C-reactive pro-

Correspondence and reprint requests should be addressed to:

Dr. Jayne Woodside

Nutrition and Metabolism Group

Centre for Public Health

Queen's University Belfast, First Floor

Institute of Clinical Science B

Grosvenor Road, Belfast, BT12 6BJ

UK

Email: j.woodside@qub.ac.uk

Fax: 02890235900 tein (CRP) $(5,6)$ and dietary factors, such as carotenoid and vitamin B status $(7,8)$. However, there is currently no information on the role of these novel cardiovascular risk factors in determining CVD risk in Cuba.

The aim of this pilot study was to assess potentially novel risk factors for CVD in an adult population in Cuba and to determine how these novel risk factors were associated with classical CVD risk factors.

\section{MATERIALS AND METHODS}

\section{Study design}

Ninety-seven adults, aged 45-60 years, receiving medical care in a policlinic (primary healthcare setting) in Havana were recruited. The exclusion criteria were adults with non-atherosclerotic CVD, current pregnancy, women breastfeeding, psychiatric disorders, cardiomyopathy, acute inflammatory conditions, acute malnutrition, systemic rheumatic diseases, gout, known chronic and acute renal failures, nephrotic syndrome, thyroid disorders, cancer, and HIV-positive or AIDS. Eligible 
participants were invited to participate by three of 15 family doctors employed within the clinic, representing $20 \%$ of the total population within relevant age range registered at the clinic. Trained general practitioners and nurses examined them for traditional and novel cardiovascular risk factors. A general questionnaire, including parental and personal medical records, was completed by the family doctor. Physical activity was assessed using the question "Compared to your friends and people of your age, how would you consider your physical activity: less than, same as, more than?" Anthropometric data included height and weight, from which body mass index (BMI) in $\mathrm{kg} / \mathrm{m}^{2}$ was calculated. Waist-circumference and hip-circumference were measured according to the established protocols, and the waist-to-hip ratio was calculated. Fasting serum samples were collected and stored at $-80{ }^{\circ} \mathrm{C}$ until analysis. Medical history, including record of psychiatric disorders, gout, acute malnutrition, cancer, rheumatic disease, neurologic and demyelinating disorders, acute and chronic renal failures, nephrotic syndrome, thyroid diseases, and HIV or AIDS, was also noted. Presence or absence of metabolic syndrome was defined according to the Adult Treatment Panel III criteria (9).

\section{Laboratory methods}

Levels of vitamin A and $\mathrm{E}$ and carotenoids in serum were assessed using high-performance liquid chromatography (HPLC) with diode array detection following extraction into heptanes (10). CRP was assessed by latex-enhanced immunoturbidimetric assay (Randox Pharmaceuticals, UK) using an ILab 600 biochemical analyzer and using the I-Lab 600 computer software (Instrumentation Laboratories Ltd., Warrington, UK). Serum lipids (total cholesterol, high-density lipoprotein (HDL)-cholesterol, and triglycerides) were analyzed using enzymatic assays (Randox Ltd., Crumlin, NI) on an I-Lab 600 autoanalyser. tHcy was determined by HPLC with detection of fluorescence according to Ubbink et al. (11). Serum folate and vitamin B12 were determined using a SimulTRAC-SNB radioassay kit (ICN Pharmaceuticals, California, USA). The QUICKI and HOMA scores, as measures of insulin resistance, were calculated from fasting glucose and insulin measures $(12,13)$. The HOMA score is fasting plasma insulin (mIU/L) $\mathrm{x}$ fasting plasma glucose/22.5 while the QUICKI score is equal to $1 /$ [log fasting plasma insulin $(\mu \mathrm{U} / \mathrm{mL})+\log$ fasting plasma glucose $(\mathrm{mg} / \mathrm{dL})]$.

\section{Statistical methods}

Continuous data were assessed for normality and logarithmically transformed where appropriate.
Data were compared between sexes, or according to published cut-off points for increased CVD risk using Student's independent samples $t$-test (continuous variables) or chi-square test (categorical variables). The associations between the continuous variables were examined using Pearson's correlation co-efficients. Multivariate analysis was carried out using general linear modelling (continuous variable outcomes) or logistic regression (categorical variable outcomes). Confounders were included if they were independently associated with the variable of interest, or were known to be associated with the variable from the scientific literature. A p value of $<0.05$ was considered significant. All statistical analyses were performed using the SPSS software for Windows (version 17.0).

\section{Ethical aspects}

The study was conducted in accordance with the Helsinki Declaration.

\section{RESULTS}

The overall risk factors and the disease-prevalence rates were: hypertension $(\geq 140 / 90 \mathrm{mmHg})$ (53.6\%); hypercholesterolaemia (total cholesterol $>5.2 \mathrm{mmol} / \mathrm{L})(47.0 \%)$; low-HDL-cholesterol $(<1.03$ $\mathrm{mmol} / \mathrm{L})(64.3 \%)$; diabetes (self-reported) (24.6\%); metabolic syndrome (ATP III criteria) (58.2\%); overweight and obesity (BMI $\geq 25 \mathrm{~kg} / \mathrm{m}^{2}$ ) (78.0\%); current smoking (39.3\%); elevated levels of CRP (3 $<$ value $<10 \mathrm{mg} / \mathrm{L})(32.1 \%)$; low lipid-standardized vitamin E levels ( $<5 \mu \mathrm{mol} / \mathrm{mmol}$ total cholesterol) (69.6\%); and high tHcy levels (>15 $\mu \mathrm{mol} / \mathrm{L})$ (11.1\%).

The distribution of demographic variables and traditional CVD risk factors is presented by sex in Table 1 and of more novel risk factors by sex in Table 2. Women had a significantly lower waistcircumference and waist-to-hip ratio and higher HDL-cholesterol but also higher total cholesterol. A higher proportion reported being diabetic and women reported taking less physical activity than men. The folate status was significantly higher in women than in men but the $\alpha$-carotene status was significantly lower in women than in men.

We then explored how closely the novel risk factors assessed were associated with the traditional CVD and diabetes risk factors. Of the novel risk factors assessed, the total carotenoid status was most closely associated with the status of traditional risk factor in unadjusted analyses, being negatively associated with BMI ( $\mathrm{r}=-0.38, \mathrm{p}<0.01)$, waist-circumference $(\mathrm{r}=-0.36, \mathrm{p}=0.01)$, triglycerides $(\mathrm{r}=-0.25, \mathrm{p}<0.05)$, and HOMA score $(\mathrm{r}=-0.26, \mathrm{p}<0.05)$ and positively 


\begin{tabular}{|c|c|c|c|}
\hline Variable or risk factor & Males $\left(\mathrm{n}_{\max }=46\right)$ & Females $\left(\mathrm{n}_{\max }=51\right)$ & $\mathrm{p}$ value \\
\hline Age (years) & $54.7(6.0)$ & $54.1(6.7)$ & 0.61 \\
\hline Systolic blood pressure (mmHg) & $139.0(15.1)$ & $143.6(23.3)$ & 0.36 \\
\hline Diastolic blood pressure (mmHg) & $83.2(8.4)$ & $85.1(11.9)$ & 0.48 \\
\hline $\begin{array}{l}\text { Hypertensive }(>140 / 90 \mathrm{mmHg}) \\
\text { Not hypertensive }(<140 / 90 \mathrm{mmHg})\end{array}$ & $\begin{array}{l}48.1 \\
51.9\end{array}$ & $\begin{array}{l}57.1 \\
42.9\end{array}$ & 0.47 \\
\hline Body mass index $\left(\mathrm{kg} / \mathrm{m}^{2}\right)$ & $27.5(4.0)$ & $29.5(5.9)$ & 0.14 \\
\hline$\%$ of normal weight $\left(<25 \mathrm{~kg} / \mathrm{m}^{2}\right)$ & 26.9 & 19.0 & 0.18 \\
\hline$\%$ of overweight $\left(25-29.9 \mathrm{~kg} / \mathrm{m}^{2}\right)$ & 50.0 & 35.7 & \\
\hline$\%$ of obese $\left(>30 \mathrm{~kg} / \mathrm{m}^{2}\right)$ & 23.1 & 45.2 & \\
\hline Waist-circumference (cm) & $98.4(10.6)$ & $91.7(12.0)$ & 0.03 \\
\hline Waist-to-hip ratio & $0.95(0.06)$ & $0.85(0.06)$ & $<0.001$ \\
\hline Total cholesterol (mmol/L) & $4.96(1.03)$ & $5.42(1.03)$ & 0.047 \\
\hline HDL-cholesterol (mmol/L) & $0.86(0.26)$ & $1.03(0.36)$ & 0.02 \\
\hline Triglycerides (mmol/L) & $1.88(0.66)$ & $1.90(0.68)$ & 0.89 \\
\hline$\%$ of current smokers & 32.5 & 44.9 & 0.23 \\
\hline$\%$ of diabetics & 11.1 & 33.3 & 0.04 \\
\hline$\%$ of metabolic syndrome & 55.2 & 60.5 & 0.66 \\
\hline Ethnic origin & & & 0.48 \\
\hline White & 67.4 & 56.9 & \\
\hline Mestizo (mixed) & 19.6 & 21.6 & \\
\hline Black & 13.0 & 21.6 & \\
\hline Physical activity & & & 0.02 \\
\hline$\%$ perceived self less active than others & 34.6 & 55.0 & \\
\hline$\%$ perceived self equally active to others & 42.3 & 12.5 & \\
\hline$\%$ perceived self more active than others & 23.1 & 32.5 & \\
\hline \multicolumn{4}{|c|}{$\begin{array}{l}\text { Data presented as mean (SD) for continuous variables or \% for categorical variables. P value is } \\
\text { given for the comparison of males and females. This was determined using an independent sample } \\
t \text {-test for continuous variables and a chi-square test for categorical variables. CVD=Cardiovascular } \\
\text { disease; HDL=High-density lipoprotein cholesterol; } S D=S t a n d a r d ~ d e v i a t i o n\end{array}$} \\
\hline
\end{tabular}

\begin{tabular}{|c|c|c|c|}
\hline $\begin{array}{l}\text { Novel biomarker or CVD } \\
\text { risk factor }\end{array}$ & Males $\left(\mathrm{n}_{\max }=46\right)$ & Females $\left(\mathrm{n}_{\max }=51\right)$ & $\mathrm{p}$ value \\
\hline QUICKI & $0.35(0.04)$ & $0.35(0.05)$ & 0.71 \\
\hline HOMA & $2.12(1.01,4.66)$ & $1.98(1.12,3.56)$ & 0.72 \\
\hline $\mathrm{CRP}(\mathrm{mg} / \mathrm{L})$ & $2.56(1.34,4.80)$ & $2.49(1.12,5.11)$ & 0.90 \\
\hline tHcy $(\mu \mathrm{mol} / \mathrm{L})$ & $10.6(8.3,12.4)$ & $9.2(7.4,11.2)$ & 0.16 \\
\hline Folate (nmol/L) & $19.3(12.9,27.5)$ & $24.5(18.6,30.6)$ & 0.03 \\
\hline Vitamin B12 (pmol/L) & $309.8(181.0,471.7)$ & $330.2(214.0,471.2)$ & 0.63 \\
\hline Lipid standardized vitamin $\mathrm{E}(\mu \mathrm{mol} / \mathrm{mmol})$ & $4.53(1.41)$ & $4.72(1.63)$ & 0.59 \\
\hline Total carotenoids $(\mu \mathrm{mol} / \mathrm{L})$ & $0.85(0.63,1.36)$ & $0.85(0.56,1.28)$ & 0.99 \\
\hline$\alpha$-carotene $(\mu \mathrm{mol} / \mathrm{L})$ & $0.08(0.05,0.13)$ & $0.05(0.03,0.09)$ & 0.048 \\
\hline$\beta$-carotene $(\mu \mathrm{mol} / \mathrm{L})$ & $0.19(0.13,0.31)$ & $0.21(0.13,0.34)$ & 0.66 \\
\hline \multicolumn{4}{|c|}{$\begin{array}{l}\text { Data presented as mean (SD) for continuous variables, except for HOMA score, CRP, tHcy, folate, vitamin } \\
\text { B12, total carotenoid status, } \alpha \text {-carotene and } \beta \text {-carotene status where variables were logarithmically } \\
\text { transformed and presented as geometric mean (interquartile range). P value is given for the comparison } \\
\text { of males and females. This was determined using an independent sample } t \text {-test for continuous variables } \\
\text { and a chi-square test for categorical variables. CRP=C-reactive protein; CVD=Cardiovascular disease; } \\
\text { SD=Standard deviation }\end{array}$} \\
\hline
\end{tabular}




\begin{tabular}{|c|c|c|c|c|}
\hline Risk factor & $\begin{array}{c}\text { Model } 1 \\
\text { Mean }(95 \% \text { CI) }\end{array}$ & $\mathrm{p}$ value & $\begin{array}{c}\text { Model } 2 \\
\text { Mean }(95 \% \mathrm{CI})\end{array}$ & $\mathrm{p}$ value \\
\hline BMI & $-8.2(-14.4,-2.1)$ & $\mathrm{p}=0.01$ & $-7.9(-5.9,0.2)$ & 0.054 \\
\hline Waist-circumference & $-21.0(-34.5,-7.5)$ & $\mathrm{p}=0.003$ & $-21.2(-39.4,-3.0)$ & 0.026 \\
\hline Waist-to-hip ratio & $-0.04(-0.11,0.03)$ & $\mathrm{p}=0.21$ & $-0.05(-0.17,0.08)$ & 0.46 \\
\hline
\end{tabular}

associated with tHcy $(\mathrm{r}=0.31, \mathrm{p}<0.01)$ and QUICKI score $(r=0.26, p=0.03)$. The total carotenoid status was significantly lower in diabetics compared to non-diabetics [diabetics 0.592 (1.74); non-diabetics 0.925 (1.68), $\mathrm{p}=0.01]$; lower in those with metabolic syndrome versus those without metabolic syndrome [metabolic syndrome 0.721 (1.69); without metabolic syndrome 0.970 (1.66), $\mathrm{p}=0.03$ ] and differed among BMI categories, being higher in those of normal weight than in those who were overweight or obese [normal weight 1.221 (1.46); overweight 0.831 (1.63); and obese 0.679 (1.86), $\mathrm{p}=0.02]$. The total carotenoid status did not differ between smokers and non-smokers [non-smokers 0.895 (1.66); smokers 0.740 (1.87), $\mathrm{p}=0.17]$.

The variables described above in univariate analyses were entered into separate multivariate regression models with the traditional risk factor or condition as the dependent variable and the total carotenoid status as an explanatory variable. These models were initially adjusted for age, sex, cholesterol, and smoking status, and then additionally for ethnic origin, carotene intake, physical activity, hypercholesterolaemia, and hypertension (Table 3). The total carotenoid status was significantly negatively associated with waist-circumference and BMI after initial adjustment, and this remained significant for waist-circumference but just lost significance for BMI ( $\mathrm{p}=0.054)$ after further adjustment. Similarly, in logistic regression models, with diabetes or metabolic syndrome as outcome variables, the total carotenoid status was significantly associated with risk of being diabetic $[\operatorname{Exp}(B)=-0.035, p=0.04]$ or having metabolic syndrome $[\operatorname{Exp}(\mathrm{B})=-0.035$, $\mathrm{p}=0.035$ ] (logistic regression analyses only adjusted for age, sex, total cholesterol, and smoking status).

\section{DISCUSSION}

This study has examined the traditional and novel CVD risk factor status of urban people aged 40-65 years in Cuba. In general, there was a high prevalence of traditional CVD risk factors in particular, such as hypertension, high cholesterol, low-HDLcholesterol, and smoking, and a high prevalence of metabolic syndrome. The total serum carotenoid status was the novel CVD risk factor most closely associated with an increased prevalence of CVD risk factors.

Rodriguez et al. recently examined the trends in mortality due to coronary heart diseases (CHDs) in the Americas during 1970-2000 (2), and although reduction in mortality due to CHDs was observed for Cuba, the rates of mortality due to CHDs in Cuba were still the highest among women compared to other countries in the Americas and the third highest in men. The authors concluded that recent reductions in mortality due to $\mathrm{CHDs}$ were less favourable in Latin America than in the USA and Canada and that this may reflect unfavourable changes in nutrition (including obesity), physical activity, and smoking, together with less-effective control of hypertension and management of CHDs.

Cuba experienced an economic crisis in the early 1990s, triggered by the collapse of the Soviet Union and a reinforced US blockade and characterized by a shortage of fuel, food and essential supplies $(4,14)$. Per-capita energy availability and physical activity increased, and the prevalence of obesity decreased. This was followed by a period of economic recovery, and Cuba now occupies an unusual position as a non-industrialized country with a well-developed public-health sector, which has eliminated epidemic infectious diseases, has low infant mortality, and a long life expectancy (15). To our knowledge, this is the first study to examine both traditional and novel risk factor status in a Cuban population since the nutrition transition in the 1990s.

Even for the traditional CVD risk factors, there are few published data with which to compare our results. Cooper et al. have summarized the available data (15). Our overall prevalence rates for hypertension (age-group: 40-65 years; 53.6\%) were somewhat higher than that reported in other literature [15-74 years; $25 \%$ (16) and (35-64 years; 34\%) (17)] but this may reflect the urban centre from which we recruited our sample, the more recent sampling 
time, and the slightly older age range used. The current smoking status was similar in our population to other reports (15). The obesity rates in the present study were also somewhat higher than what had been reported previously (23\% of males and $45 \%$ females compared to $8 \%$ of males and $14 \%$ of females) (16), with reasons for these differences likely to be as for hypertension. Our data relating to lipid concentrations and the prevalence of metabolic syndrome are, to our knowledge, among the first to be reported in the last decade.

For the more novel risk factors, even fewer comparisons with published literature can be drawn. Cut-points for the increased CHD risk remain to be firmly established for many of these factors but for lipid-standardized vitamin $\mathrm{E}$ and $\mathrm{tHcy}$, cut-points of $5 \mu \mathrm{mol} / \mathrm{mmol}$ (18) and $15 \mu \mathrm{mol} / \mathrm{L}$ (19) have been suggested respectively. In the present study, using these cut-points, $69.6 \%$ and $11.1 \%$ of the population can be considered at an elevated risk of CHD based on lipid-standardized vitamin E and tHcy. For CRP, the American Heart Association has suggested that the serum CRP values of $>10 \mathrm{mg} / \mathrm{L}$ imply the presence of active infection or inflammation but that values between 3 and $10 \mathrm{mg} / \mathrm{L}$ are indicative of an increased risk of CVDs (20). Using this cut-point suggests that just under one-third of this population is at an increased risk of CVDs in terms of CRP concentrations.

The consistent associations observed between the total carotenoid status and the traditional risk factors for CVDs and diabetes and risk of diabetes and metabolic syndrome are of interest and have recently been reported in a number of larger epidemiological studies. Akbaraly et al. reported that elderly subjects in the highest quartile of total plasma carotenoids had a reduced nine-year risk of dysglycaemia compared to participants in the lowest quartile [relative risk $(\mathrm{RR})=0.42,95 \%$ confidence interval (CI) 0.22-0.82], and the same investigators also demonstrated an association with mortality (22). Similarly, in a cross-sectional analysis of middle-aged and older women, Wang et al. showed an association between individual plasma carotenoids, although they did not look at total carotenoid status, smoking, obesity, low-density lipoprotein-cholesterol (LDL), HDL-cholesterol, HbA1c, and CRP (23). Finally, Farwell et al. demonstrated a cross-sectional association between total plasma carotenoids and current smoking, alcohol ingestion, lipids (total-, HDL- and LDL-cholesterol), and ICAM-1 in middle-aged men (24). It is not apparent from any of these studies whether the total plasma or serum carotenoid status is serving as a marker of a diet high in fruit and vegetable consumption, as a marker of other protective lifestyle habits and health behaviours, or whether they are directly having an effect of CVD risk factors but these relatively consistent associations do deserve further exploration.

\section{Limitations}

The present study had several limitations. It was a small and cross-sectional study in nature, and therefore, no causal relationships can be directly assessed. It was also not taken from a truly representative sample of the Cuban population but served as a pilot study of the application of epidemiological research methods and the determination of novel cardiovascular risk factor status in Cuba. For that reason, the conclusions are only valid for the population studied (i.e. patients aged 45-60 years from an urban setting) and cannot be extrapolated to other Cuban populations. As numbers were small, the conclusions must also be interpreted cautiously, as the multivariate adjustment carried out, with adjustment for up to nine covariates, may have produced false significant associations. Nevertheless, it is one of the first studies since the nutrition transition in the 1990s to examine the status of traditional CVD risk factors and the status of novel CVD risk factors. It has also examined how the status of novel cardiovascular risk factors in a Cuban population relates to the status of traditional cardiovascular risk factors.

\section{Conclusions}

In this small unrepresentative population sample, classical CVD risk factors were highly prevalent among people aged 40-65 years in Havana city. The main traditional risk factors present were hypertension, low-HDL-cholesterol, and overweight/obesity while over one-third of this population was at any elevated risk of CVDs through high CRP concentrations and more than two-thirds at an elevated risk in terms of their lipid-standardized vitamin E status. The total serum carotenoid status in this small sample appeared to be inversely associated with an increased prevalence of CVD risk factors.

\section{ACKNOWLEDGEMENTS}

The study was funded by an International Joint Project Scheme award from the Royal Society.

\section{REFERENCES}

1. Cuba. Ministerio de Salud Pública. Anuario Estadístico de Salud. Principales causas de muerte de todas las edades 1970, 1981, 1993, 2001-2002. Havana: Ministerio de Salud Pública, Government of Cuba, 2002.

2. Rodriguez T, Malvezzi M, Chatenoud L, Bosetti C, Levi F, Negri E. Trends in mortality from coronary heart and cerebrovascular diseases in the Americas: 
1970-2000. Heart 2006;92:453-60.

3. Food and Agriculture Organization. Nutrition country profiles—Cuba. (http://www.fao.org/ag/agn/nutrition/cub_en.stm, accessed on 12 September 2011).

4. Canero AH. Mortality from ischemic heart disease in Cuba. The role of diet and serum cholesterol. Rev Cubana Cardiolog Cirugía Cardiovas 1999;13:8-12.

5. Libby P, Ridker PM. Inflammation and atherothrombosis: from population biology and bench research to clinical practice. J Am Coll Cardiol 2006;48:33-46.

6. Corson MA. Emerging inflammatory markers for assessing coronary heart disease risk. Curr Cardiol Rep 2009;11:452-9.

7. $\mathrm{Hu}$ FB, Willett WC. Optimal diets for prevention of coronary heart disease. JAMA 2002;288:2569-78.

8. Mente A, de Koning L, Shannon HS, Anand SS. A systematic review of the evidence supporting a causal link between dietary factors and coronary heart disease. Arch Intern Med 2009;169:659-69.

9. National Cholesterol Education Program. Third report of the National Cholesterol Education Program (NCEP) expert panel on detection, evaluation, and treatment of high blood cholesterol in adults (Adult Treatment Panel III). Final report. Circulation 2002;106:3143-421.

10. Craft NE, Wise SA, Soares JH. Optimization of an isocratic high-performance liquid chromatographic separation of carotenoids. J Chromatogr 1992;589:171-6.

11. Ubbink JB, Vermaak WJH, Bissbort S. Rapid highperformance liquid chromatographic assay for total homocysteine levels in human serum. J Chromatogr 1991;565:441-6.

12. Matthews DR, Hosker JP, Rudenski AS, Naylor BA, Treacher DF, Turner RC. Homeostasis model assessment: insulin resistance and beta-cell function from fasting plasma glucose and insulin concentrations in man. Diabetologia 1985;28:412-9.

13. McClenaghan NH. Determining the relationship between dietary carbohydrate intake and insulin resistance. Nutr Res Rev 2005;18:222-40.

14. Rodríguez-Ojea A, Jiménez S, Berdasco A, Esquivel M. The nutrition transition in Cuba in the nineties: an overview. Public Health Nutr 2002;5:129-33.

15. Cooper RS, Ordunez P, Ferrer MDI, Munoz JL, Espinosa-Brito A. Cardiovascular disease and associated risk factors in Cuba: prospects for prevention and control. Am J Public Health 2006;96:94-101.

16. Ordúñez P, Barceló A, Bernal JL, Espinosa A, Silva LC, Cooper RS. Risk factors associated with uncontrolled hypertension: findings from the baseline CARMEN survey in Cienfuegos, Cuba. J Hypertens 2008;26:66371.

17. Wolf-Maier K, Cooper RS, Banegas JR, Giampaoli $\mathrm{S}$, Hense HW, Joffres $\mathrm{M}$ et al. Hypertension prevalence and blood pressure levels in 6 European countries, Canada, and the United States. JAMA 2003;289: 2363-9.

18. Gey KF. Vitamins E plus C and interacting conutrients required for optimal health. A critical and constructive review of epidemiology and supplementation data regarding cardiovascular disease and cancer. Biofactors 1998;7:113-74.

19. Refsum H, Smith AD, Ueland PM, Nexo E, Clarke $\mathrm{R}, \mathrm{McPartlinJ}$ et al. Facts and recommendations about total homocysteine determinations: an expert opinion. Clin Chem 2004;50:3-32.

20. Pearson TA, Mensah GA, Alexander RW, Anderson JL, Cannon RO, Criqui M et al. Markers of inflammation and cardiovascular disease: application to clinical and public health practice: a statement for healthcare professionals from the Centers for Disease Control and Prevention and the American Heart Association. Circulation 2003;107:499-511.

21. Akbaraly TN, Fontbonne A, Favier A, Berr C. Plasma carotenoids and onset of dysglycemia in an elderly population: results of the Epidemiology of Vascular Ageing Study. Diabetes Care 2008;31:1355-9.

22. Akbaraly TN, Favier A, Berr C. Total plasma carotenoids and mortality in the elderly: results of the Epidemiology of Vascular Ageing (EVA) Study. Br J Nutr 2009;101:86-92.

23. Wang L, Gaziano JM, Norkus EP, Buring JE, Sesso HD. Associations of plasma carotenoids with risk factors and biomarkers related to cardiovascular disease in middle-aged and older women. Am J Clin Nutr 2008;88:747-54.

24. Farwell WR, Gaziano JM, Norkus EP, Sesso HD. The relationship between total plasma carotenoids and risk factors for chronic disease among middle-aged and older men. Br J Nutr 2008;100:883-9. 